\title{
The Mechanism of and Preventive Therapy for Stroke in Patients with Atrial Fibrillation
}

\author{
Young-Hoon Kim, Seung-Young Roh \\ Cardiology Division, Korea University Medical Center, Seoul, Korea
}

Atrial fibrillation is a major cardiac cause of stroke, and a pathogenesis involving thrombus formation in patients with atrial fibrillation is well established. A strategy for rhythm control that involves catheter ablation and anticoagulation therapy is evolving. A strategy for rhythm control that restores and maintains sinus rhythm should reduce the risk of ischemic stroke that is associated with atrial fibrillation; however, this is yet to be proven in large-scale randomized controlled trials. This paper reviews the emerging role of rhythm control therapy for atrial fibrillation to prevent stroke.

Keywords Atrial fibrillation; Ischemic stroke; Thromboembolism; Catheter ablation; Rhythm control
Correspondence: Young-Hoon Kim Division of Cardiology, Korea University Medical Center, 73 Inchon-ro, Seongbukgu, Seoul 02841, Korea Tel: $+82-2-920-6394$

Fax: +82-2-927-1478 E-mail:yhkmd@unitel.co.kr

Received: April 4, 2016 Revised: May 20, 2016 Accepted: May 20, 2016

The authors have no financial conflicts of interest.

\section{Introduction}

Atrial fibrillation (AF) is the most common sustained cardiac arrhythmia, and it is a global problem. ' Compared with normal, age-matched control subjects, AF increases the risk of ischemic stroke by $4-5$ fold. ${ }^{2,3}$ Stroke is the second most common cause of death and it is the main cause of disability. ${ }^{4}$ The prevalence of AF and the associated stroke risk are higher among elderly patients. The stroke risk is independent of whether the AF is paroxysmal, persistent, or permanent. Paroxysmal AF often causes a cryptogenic ischemic stroke or a transient ischemic attack (TIA). Embolisms with cardiac origins cause between $17 \%$ and $30 \%$ of all ischemic strokes, but it is estimated that the causes of up to $40 \%$ of ischemic strokes are unknown. ${ }^{5}$ Recent developments in monitoring devices have provided more robust evidence of an association between AF and stroke, especially cryptogenic stroke. Newly detected AF is identified in 10\% of the patients who experience a stroke or a TIA, and an additional $11 \%$ cases of AF are newly detected when patients undergo 30 days of continuous electrocardiographic monitoring. ${ }^{6-8}$
A key approach towards the management of $A F$ is to reduce the risk of stroke by using oral anticoagulation (OAC) therapy. The novel oral anticoagulants are not inferior to warfarin for preventing stroke in nonvalvular $\mathrm{AF}_{1}^{9-11}$ and they are the preferred OAC option for patients who are at high risks of ischemic stroke and have congestive heart failure, hypertension, age $\geq 75$ years, diabetes mellitus, and prior stroke or TIA or thromboembolism ( $\mathrm{CHADS}_{2}$ ) score or a $\mathrm{CHA}_{2} \mathrm{DS}_{2}$-vascular disease, age 65-74 years, and sex category (VASc) score of $\geq 1$ or 2 . Left atrial appendage (LAA) occlusion devices are not inferior to warfarin, and they help patients who have the contraindications associated with the long-term use of OAC therapy and high risks of bleeding during OAC therapy. ${ }^{12,13}$ Furthermore, rhythm control using catheter ablation is an emerging treatment option for AF. Catheter ablation is more efficient at reducing the AF burden compared with antiarrhythmic drugs (AADs). However, the effectiveness of catheter ablation at reducing the risks of mortality and stroke is not yet evident. The current American Heart Association, American College of Cardiology, and Heart Rhythm Society guidelines suggest that catheter ablation for AF should not be performed 
on patients who cannot be treated with OAC therapy during and after the procedure. Catheter ablation for AF to restore sinus rhythm should not be performed with the sole intent of obviating the need for OAC therapy. There is insufficient evidence available to determine whether catheter ablation for AF reduces all-cause mortality, stroke, and heart failure.

Thromboembolic events in the control arm of the RAte Control versus Electrical cardioversion study were more common in the patients who had stopped OAC therapy or had unsatisfactory international normalized ratios. ${ }^{14}$ Similarly, most of the patients who experienced strokes in the Atrial Fibrillation Follow-Up Investigation of Rhythm Management study were not receiving warfarin or they had suboptimal international normalized ratios at the times of their strokes. ${ }^{15}$ Clearly, the premature cessation of OAC therapy in one-third of the rhythm-controlled patients in the Atrial Fibrillation Follow-Up Investigation of Rhythm Management trial rendered them vulnerable to thromboembolic consequences. The strategy underlying AF treatment to reduce the risk of stroke is evolving, especially in the era of novel OAC therapies.

\section{Atrial fibrillation and cryptogenic stroke}

AF is a major independent predictor of ischemic stroke. The estimated risk of AF during a lifetime is between 22\% and $26 \% .{ }^{16} \mathrm{AF}$ is associated with abnormal blood stasis that involves atrial hypocontractility and the loss of the atrial kick, atrial structural remodeling, and the activation of platelets and the coagulation cascade, which is known as Virchow's triad. In addition, $\mathrm{AF}$ provides a prothrombotic environment through atrial dilation and stretching, a reduction in the pectinate muscle volume, the loss of a normal endocardial surface, endothelial dysfunction, and the release of coagulation factors, namely, factor $\mathrm{Xa}$ and thrombin. These AF characteristics promote thrombus formation and ischemic stroke. AF is a significant underlying cause of cardiac emboli in approximately 50\% of patients. Stroke of an unknown cause is more frequent in younger patients. Cryptogenic stroke causes up to $40 \%$ of the strokes in patients who are $<50$ years of age. It is difficult to establish a treatment strategy for stroke that has a cryptogenic cause. Although a cardiac origin for emboli may be suspected, it is difficult to verify, especially when inadequate monitoring devices are used. The most commonly used devices for monitoring arrhythmias are 24 -48 hours Holter and event monitors. However, the AF detection rate for these devices is between $2.5 \%$ and $16 \% . .^{17,18}$

The data from recently implanted devices show that the prevalence of $\mathrm{AF}$ is higher in association with cryptogenic stroke. AF or atrial tachycardia (AT) is common among the arrhythmias, and this has been determined from the interrogation of the devices. The specificity of AF or AT detection using implantable devices is 98.5\%. The findings from the Atrial Fibrillation Reduction Atrial Pacing Trial showed that ischemic stroke was associated with the occurrence of subclinical AF (hazard ratio [HR], 1.76; 95\% confidence interval $[\mathrm{Cl}], 0.99-3.11 ; P=0.05) .{ }^{19}$ The IMPACT trial was designed to test the hypothesis that remote monitoring would guide the initiation and cessation of the administration of OAC therapy to patients with implanted devices and would improve clinical outcomes by reducing the stroke risk, the development of systemic embolisms, and major bleeding. ${ }^{20,21}$ The investigators randomized 2,718 patients with dual-chamber and biventricular defibrillators to start and stop the administration of OAC therapy using remote rhythm monitoring or ordinary officebased follow-up assessments that involved determining anticoagulation using standard clinical criteria. The primary events, including stroke, systemic embolism, and major bleeding, did not differ between the group of patients whose rhythms were remotely monitored (2.4 per 100 patient-years) and those who underwent ordinary office-based follow-up assessments (2.3 per 100 patient-years) (HR, 1.06; 95\% Cl, 0.75-1.51; $P=0.732)$. Within the group of patients with $A T$, the thromboembolism rates were 1.0 per 100 patient-years for those whose rhythms were remotely monitored and 1.6 per 100 patient-years for those who underwent office-based follow-up assessments (relative risk, $-35.3 \% ; 95 \% \mathrm{Cl}_{1}-70.8-35.3 \% ; P=0.251$ ). Although there was no temporal relationship between AT and stroke, the AT burden was associated with thromboembolism.

\section{Atrial myopathy and atrial fibrosis}

In relation to anatomical remodeling, endothelial dysfunction, which includes fibrotic changes in patients with $A F$, has been defined as atrial myopathy. The findings from previous studies have shown a relationship between the formation of thrombi and atrial fibrosis. ${ }^{22,23}$ Atrial fibrosis and a decline in the contractility of the left atrial (LA) myocardium result in blood flow stasis, especially within the LAA. An inverse relationship between flow and the $\mathrm{CHA}_{2} \mathrm{DS}_{2}$-VASc score has been determined. The parameters that comprise the $\mathrm{CHA}_{2} \mathrm{DS}_{2}$-VASc score and the factors associated with a decline in the LAA flow velocity on transesophageal echocardiography often overlap, which means that LA myopathy with remodeling is associated with an increased risk of stroke in patients with $\mathrm{AF}^{24-26}$

Areas showing late gadolinium enhancement (LGE) on cardiovascular magnetic resonance images have been used to detect atrial fibrosis. ${ }^{27-29}$ While T1 mapping was developed to identify 
diffuse myocardial fibrosis, it has recently been applied to the left atrium, and it has a correlation with the LA electrogram voltage. ${ }^{30}$ The LGE area in the left atrium is related to a reduced LAA flow velocity and the clinical outcomes after treatment. ${ }^{31}$ LGE cardiovascular magnetic resonance imaging of the left atrium is a noninvasive technique that assesses the structure and function of the heart. Its advantages are associated with not exposing patients to radiation, the high temporal resolution, and the functional analyses. It is also useful to determine the tissue composition of the left atrium. However, the application of and the LGE techniques have not been standardized, and there are some technical problems to be resolved. The atrial myocardial wall is too thin to accurately analyze the LGE area using cardiovascular magnetic resonance imaging. The irregular ventricular rhythms render functional analyses complex during AF. However, in the near future it has the potential to be a valuable method for predicting clinical outcomes, including the stroke risk.

\section{The role of the left atrial appendage in cardioembolic stroke}

Complex structures with areas of relatively low flow predispose patients to stasis, especially during AF. In patients with nonvalvular AF, 90\% of the thrombi are located in the LAA. LAA enlargements and reductions in LAA flow velocities are associated with increases in thrombus formation and stroke. ${ }^{32-34}$ Patients with AF undergo remodeling of the LAA in association with increased appendage volumes.

The findings from a study undertaken by Mügge et al. ${ }^{35}$ showed that the group of patients with nonvalvular AF had an increased risk of thrombosis, especially in the subgroup with a low LAA emptying flow rate of $<250 \mathrm{~mm} / \mathrm{s}$. The incidence of ischemic stroke and peripheral embolic events in the subgroup with a low flow rate was significantly higher $(60 \%)$ than that in the subgroup with a high flow rate of $\geq 250 \mathrm{~mm} / \mathrm{s}(5 \%)$.

A more specific representation of LAA morphology classifies the LAA shapes into four types, namely, the chicken wing, windsock, cactus, and cauliflower categories. The findings from previous studies have shown that the non-chicken wing types are associated with a greater risk of stroke than the chicken wing type, and that the highest risk is associated with the cauliflower type, even in patients with low $\mathrm{CHADS}_{2}$ scores. However, the findings from other investigations have not demonstrated a relationship between these specific morphologies and the stroke risk. ${ }^{36-39} \mathrm{~A}$ greater LAA complexity, including more extensive trabeculation and multiple lobes, has been associated with an increased stroke risk, but further studies are warranted to confirm these results.

\section{Endothelial dysfunction and hypercoagulability}

Damaged or dysfunctional endothelium may lead to the release of prothrombotic and proinflammatory molecules, including von Willebrand factor (vWF), selectins, and asymmetrical dimethyl arginine, and an increase in the vascular tone and/or a reduction in vascular reactivity. Flow-mediated dilation, a clinical indicator of endothelial integrity, declines in AF patients, and is reversed with normal sinus rhythm maintenance after catheter ablation. ${ }^{40}$ Flow-mediated dilation is inversely related to the serum C-reactive protein levels in chronic AF patients, which implies disruption caused by inflammation. ${ }^{41}$ However, this continuum of endothelial dysfunction and damage appears to accentuate the highly complex pathophysiological processes involved and it perpetuates disease progression in AF. More recently, quantifying the circulating endothelial cells has been proposed as an additional measure of endothelial damage. ${ }^{42}$

The circulating C-reactive protein level is elevated in patients with $\mathrm{AF}$ compared with those who do not have AF histories, and patients with persistent $A F$ have higher $C$-reactive protein levels than those with paroxysmal $\mathrm{AF}^{43} \mathrm{An}$ association has been reported between inflammation and the stroke risk in AF patients. Indeed, high-sensitivity C-reactive protein levels have been shown to be positively correlated with stroke risk factors, including diabetes and hypertension, in AF patients and they have also been shown to be associated with mortality and a composite outcome of ischemic stroke, myocardial infarction, and vascular death. ${ }^{44}$

The findings from a study by Lip et al. ${ }^{45}$ demonstrated the presence of raised $\mathrm{VWF}$ levels in patients with chronic AF that were independent of the underlying structural heart disease. Structural abnormalities within the LA endocardium have been associated with the circulating vWF levels. Abnormal vWF levels also correlate with the risk factors for thrombosis that were identified using transesophageal echocardiography. Indeed, Heppell et al. ${ }^{46}$ reported that raised levels of VWF correlated with spontaneous echo contrast and the presence of LA thrombi in patients with non-rheumatic AF. An advanced age, prior cerebral ischemia, heart failure, and diabetes were independently associated with higher levels of vWF. Importantly, adding plasma vWF levels to the clinical stroke risk factors appeared to improve the risk stratification of patients with $\mathrm{AF}^{47}$ Asymmetric dimethyl arginine is an endogenous substance produced from proteolysis of methylated arginine-related proteins. Asymmetric dimethyl arginine exerts a competitive inhibitory effect on nitric oxide synthase and it reduces the bioavailability of nitric oxide. Elevated levels of asymmetric dimethyl arginine have been reported in patients with coronary artery disease, ${ }^{48}$ hypertension ${ }_{1}^{49}$ diabe- 
tes $^{50}$ and atherosclerosis. ${ }^{51}$ However, further investigations are required into the relationship between asymmetric dimethyl arginine and thrombus formation.

\section{Rhythm control and stroke risk}

The cornerstone of stroke prevention in AF patient is OAC therapy. Accordingly, OAC therapy to prevent stroke is considered standard care for AF patients, particularly for those at higher risks. ${ }^{52}$ However, a substantial proportion of AF patients are not administered OAC therapy. ${ }^{53}$ Patient preference, complications associated with bleeding, and noncompliance are common reasons for the underuse of OAC therapy in routine clinical practice..$^{54}$ OAC therapy is often accompanied by a risk of bleeding. In clinical trials, the annual rates of major bleeding were 3.1\%$3.4 \%$ in the warfarin-treated patients and $2.1 \%-3.6 \%$ in those treated with novel OAC agents. ${ }^{9-11}$ Silent stroke is associated with elevated risks of clinical stroke and cognitive decline and a twofold increase in the risk of dementia. ${ }^{55}$ Silent stroke is common in AF patients, with an estimated prevalence of between $11 \%$ and $48 \%$ that was determined from neuroimaging studies ${ }^{56-59}$ Since $A F$ is associated with cognitive impairment and dementia ${ }_{1}^{60}$ it is conceivable that silent stroke may be the causative link. ${ }^{58,61}$

Noninvasive rhythm control strategies to restore sinus rhythm using AADs or "pharmacologic cardioversion" and direct electrical currents or "electrical cardioversion" are widely used. They are useful for patients who do not tolerate rate control drugs or patients with refractory symptoms. Maintenance of sinus rhythm with AAD has been considered to reduce stroke in AF patients ideally. However, the findings from clinical trials have failed to show any differences between rhythm control using AADs and rate control with respect to reducing the risks of ischemic stroke or systemic thromboembolism. ${ }^{14,15}$ Rhythm control using AADs is not effective at maintaining sinus rhythm, and the 1-year efficacy rates vary from $30 \%$ to $60 \% .^{52}$ In addition, the rate of AAD discontinuation is high at 10\% per year, which further diminishes the likelihood of maintaining sinus rhythm. ${ }^{62}$ The published success rates for the elimination of AF using catheter ablation dramatically exceed those associated with AADs. ${ }^{63-65}$

Catheter ablation has emerged as the rhythm control strategy for symptomatic AF. It was superior to AADs at reducing AF recurrences in drug-refractory patients. ${ }^{66}$ Analyses of the data within large health-oriented databases have demonstrated lower rates of stroke or TIA in patients who underwent catheter ablation for AF compared with those who did not undergo catheter ablation for $\mathrm{AF}^{67-69}$ Catheter ablation is commonly used to isolate arrhythmogenic myocardial tissue via energy delivery. The catheter uses an energy source, for example, radiofrequency en- ergy, cryo energy, or laser energy, to create a scar tissue lesion. It is generally less invasive than surgery for AF. In some cases, balIoon catheters or catheters with unique designs are used for catheter ablation for AF. The findings from a previous study have shown that the pulmonary veins are a main trigger of $\mathrm{AF}^{70}$ Hence, catheter ablation for AF usually consists of pulmonary vein isolation and elective substrate modification.

Catheter ablation for AF for the maintenance of sinus rhythm has led to the discontinuation of OAC therapy in selected patients whose ablation procedures were successful. Some studies' reports describe very low rates of ischemic stroke among patients whose OAC therapy was discontinued after successful catheter ablation for $\mathrm{AF}^{71-77}$ Most patients had low baseline stroke risks with $\mathrm{CHADS}_{2}$ scores of $<2$, and the risk of stroke or TIA was very low at $<0.7 \%$ per year. Some studies had followup durations that were $<3$ years. Vitamin $\mathrm{K}$ antagonists were the OAC agents of choice. All of the studies were non-randomized and retrospective, and the follow-up durations were relatively short. None of the studies employed continuous AF monitoring using implantable loop recorders to assess late AF recurrences following evident success. Only a small percentage $(<25 \%)$ of the patients were at a high risk of stroke, that is, a $\mathrm{CHADS}_{2}$ score of 2, and asymptomatic strokes were not assessed. The findings from a recent study that analyzed Swedish health registry data from a large population, showed that compared with propensity score-matched control subjects who received medical treatment, catheter ablation can prevent ischemic strokes. ${ }^{78}$ Although this was a nonrandomized retrospective study, catheter ablation was associated with a lower risk of ischemic stroke $(\mathrm{HR}, 0.69 ; 95 \% \mathrm{Cl}, 0.51-0.93)$. Interestingly, it was also associated with a lower risk of mortality $(\mathrm{HR}, 0.50 ; 95 \% \mathrm{Cl}$, 0.37-0.62). The stroke reduction effect was more pronounced among patients with $\mathrm{CHA}_{2} \mathrm{DS}_{2}$-VASc scores of $\geq 2$ (HR, 0.39 ; 95\% $\mathrm{Cl}, 0.19-0.78)$.

Ongoing clinical trials, namely, the Catheter Ablation Versus Antiarrhythmic Drug Therapy for Atrial Fibrillation trial and the Early Therapy of Atrial Fibrillation for Stroke Prevention Trial, should provide new information that will help to determine whether catheter ablation for AF is superior to standard therapy with either rate control or rhythm control drugs at reducing total mortality and other secondary outcome measures. These important trials will help to address whether catheter ablation provides benefits beyond quality of life improvements.

\section{Limitations of catheter ablation}

Ideally, catheter ablation to treat AF should help to prevent ischemic stroke. However, there is no robust evidence available 
that can assure the safety of discontinuing OAC therapy after ablation. Catheter ablation in routine clinical practice has several limitations. The substantial recurrence rate after ablation and ineffective postablation monitoring devices attenuate the effects of catheter ablation. A number of centers have reported rates of AF recurrence within 1 year of catheter ablation of between $15 \%$ and $40 \% .^{79-82}$ The recurrence of AF after ablation is usually monitored using outpatient clinic-based Holter electrocardiography event recorders. These monitoring devices only disclose patients' rhythms during extremely short timeframes relative to their entire lifetimes. Thromboembolic events often occur without evidence of AF recurrences. Although patients with implantable devices can be closely observed, they only represent a minority of the patients who require monitoring. The clinical significance of atrial high-rate episodes that are detected using device diagnostics is not yet evident, and whether we can define an atrial high-rate episode as a recurrence or whether an atrial high-rate episode increases the thromboembolic risk remains uncertain.

Innovations in ablation techniques and discovering recurrence predictors can reduce postprocedural recurrences and, hence, the thromboembolic risk. However, more sensitive monitoring methods are needed to provide the necessary assurance that OAC therapy can be discontinued after catheter ablation.

\section{Conclusions}

The stroke risk in AF patients is not only linked to the presence or absence of $A F$, but it is also related to the underlying systemic endothelial dysfunction and the presence of prothrombotic conditions. Rhythm control using AADs has failed to show benefits with respect to mortality or stroke prevention. Catheter ablation is superior to AADs in relation to the restoration and maintenance of sinus rhythm. Data are accumulating that demonstrate that patients who undergo successful catheter ablation for AF may have a low incidence of subsequent thromboembolic events. Therefore, discontinuing OAC therapy after successful ablation may result in a low thromboembolic risk and reduce the bleeding risk. OAC therapy after catheter ablation for AF should be individualized and consider not only the conventional risk score, but also the extent of the atrial fibrosis, the LAA morphology, and endothelial dysfunction.

\section{References}

1. Chugh SS, Havmoeller R, Narayanan K, Singh D, Rienstra M, Benjamin EJ, et al. Worldwide epidemiology of atrial fibrillation: a Global Burden of Disease 2010 Study. Circulation 2014;
129:837-847.

2. Phillips SJ. Is atrial fibrillation an independent risk factor for stroke? Can J Neurol Sci 1990;17:163-168.

3. Go AS, Hylek EM, Phillips KA, Chang Y, Henault LE, Selby JV, et al. Prevalence of diagnosed atrial fibrillation in adults: national implications for rhythm management and stroke prevention: the AnTicoagulation and Risk Factors in Atrial Fibrillation (ATRIA) Study. JAMA 2001;285:2370-2375.

4. Marini C, De Santis F, Sacco S, Russo T, Olivieri L, Totaro R, et al. Contribution of atrial fibrillation to incidence and outcome of ischemic stroke: results from a population-based study. Stroke 2005;36:1115-1119.

5. Sacco RL, Ellenberg JH, Mohr JP, Tatemichi TK, Hier DB, Price $T R$, et al. Infarcts of undetermined cause: the NINCDS Stroke Data Bank. Ann Neurol 1989;25:382-390.

6. Jauch EC, Saver JL, Adams HP Jr, Bruno A, Connors JJ, Demaerschalk BM, et al. Guidelines for the early management of patients with acute ischemic stroke: a guideline for healthcare professionals from the American Heart Association/American Stroke Association. Stroke 2013;44:870-947.

7. Kernan WN, Ovbiagele B, Black HR, Bravata DM, Chimowitz $M I$, Ezekowitz MD, et al. Guidelines for the prevention of stroke in patients with stroke and transient ischemic attack: a guideline for healthcare professionals from the American Heart Association/American Stroke Association. Stroke 2014; 45:2160-2236.

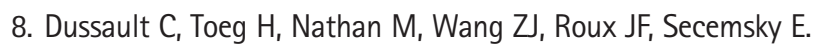
Electrocardiographic monitoring for detecting atrial fibrillation after ischemic stroke or transient ischemic attack: systematic review and meta-analysis. Circ Arrhythm Electrophysiol 2015; 8:263-269.

9. Poller L, Jespersen J, Ibrahim S. Dabigatran versus warfarin in patients with atrial fibrillation. N Engl J Med 2009;361:26732674; author reply 2674-2675.

10. Patel MR, Mahaffey KW, Garg J, Pan G, Singer DE, Hacke W, et al. Rivaroxaban versus warfarin in nonvalvular atrial fibrillation. N Engl J Med 2011;365:883-891.

11. Granger CB, Alexander JH, McMurray JJ, Lopes RD, Hylek EM, Hanna $M$, et al. Apixaban versus warfarin in patients with atrial fibrillation. N Engl J Med 2011;365:981-992.

12. Ostermayer $\mathrm{SH}$, Reisman $\mathrm{M}, \mathrm{Kramer} \mathrm{PH}$, Matthews RV, Gray WA, Block PC, et al. Percutaneous left atrial appendage transcatheter occlusion (PLAATO system) to prevent stroke in highrisk patients with non-rheumatic atrial fibrillation: results from the international multi-center feasibility trials. J Am Coll Cardiol 2005;46:9-14.

13. Holmes DR, Reddy VY, Turi ZG, Doshi SK, Sievert H, Buchbinder $M$, et al. Percutaneous closure of the left atrial appendage ver- 
sus warfarin therapy for prevention of stroke in patients with atrial fibrillation: a randomised non-inferiority trial. Lancet 2009;374:534-542.

14. Hagens VE, Crijns HJ, Van Veldhuisen DJ, Van Den Berg MP, Rienstra $\mathrm{M}$, Ranchor $\mathrm{AV}$, et al. Rate control versus rhythm control for patients with persistent atrial fibrillation with mild to moderate heart failure: results from the RAte Control versus Electrical cardioversion (RACE) study. Am Heart J 2005;149: 1106-1111.

15. Corley SD, Epstein AE, DiMarco JP, Domanski MJ, Geller N,

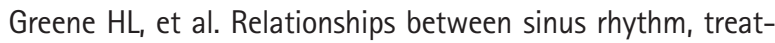
ment, and survival in the Atrial Fibrillation Follow-Up Investigation of Rhythm Management (AFFIRM) Study. Circulation 2004;109:1509-1513.

16. Andrade J, Khairy P, Dobrev D, Nattel S. The clinical profile and pathophysiology of atrial fibrillation: relationships among clinical features, epidemiology, and mechanisms. Circ Res 2014; 114:1453-1468.

17. Putaala J, Tatlisumak T. Prime time for dissecting the entity of cryptogenic stroke. Stroke 2014;45:950-952.

18. Gladstone DJ, Spring M, Dorian P, Panzov V, Thorpe KE, Hall J, et al. Atrial fibrillation in patients with cryptogenic stroke. $N$ Engl J Med 2014;370:2467-2477.

19. Brambatti M, Connolly SJ, Gold MR, Morillo CA, Capucci $A_{1}$

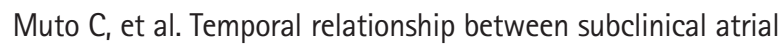
fibrillation and embolic events. Circulation 2014;129:20942099.

20. Martin DT, Bersohn MM, Waldo AL, Wathen MS, Choucair WK, Lip GY, et al. Randomized trial of atrial arrhythmia monitoring to guide anticoagulation in patients with implanted defibrillator and cardiac resynchronization devices. Eur Heart J 2015; 36:1660-1668.

21. Ip J, Waldo AL, Lip GY, Rothwell PM, Martin DT, Bersohn MM, et al. Multicenter randomized study of anticoagulation guided by remote rhythm monitoring in patients with implantable cardioverter-defibrillator and CRT-D devices: rationale, design, and clinical characteristics of the initially enrolled cohort The IMPACT study. Am Heart J 2009;158:364-370.

22. Daccarett M, Badger TJ, Akoum N, Burgon NS, Mahnkopf C, Vergara $G$, et al. Association of left atrial fibrosis detected by delayed-enhancement magnetic resonance imaging and the risk of stroke in patients with atrial fibrillation. J Am Coll Cardiol 2011;57:831-838.

23. Akoum N, Fernandez G, Wilson B, McGann C, Kholmovski E, Marrouche N. Association of atrial fibrosis quantified using LGE-MRI with atrial appendage thrombus and spontaneous contrast on transesophageal echocardiography in patients with atrial fibrillation. J Cardiovasc Electrophysiol 2013;24:
1104-1109.

24. Pollick C, Taylor D. Assessment of left atrial appendage function by transesophageal echocardiography. Implications for the development of thrombus. Circulation 1991;84:223-231.

25. Leung DY, Black IW, Cranney GB, Hopkins AP, Walsh WF. Prognostic implications of left atrial spontaneous echo contrast in nonvalvular atrial fibrillation. J Am Coll Cardiol 1994;24:755762.

26. Asinger RW, Koehler J, Pearce LA, Zabalgoitia M, Blackshear JL, Fenster PE, et al. Pathophysiologic correlates of thromboembolism in nonvalvular atrial fibrillation: ii. dense spontaneous echocardiographic contrast (The Stroke Prevention in Atrial Fibrillation [SPAF-III] study). J Am Soc Echocardiogr 1999;12: 1088-1096.

27. Habibi M, Lima JA, Khurram IM, Zimmerman SL, Zipunnikov V, Fukumoto $K$, et al. Association of left atrial function and left atrial enhancement in patients with atrial fibrillation: cardiac magnetic resonance study. Circ Cardiovasc Imaging 2015;8: e002769.

28. Mahnkopf C, Badger TJ, Burgon NS, Daccarett M, Haslam TS,

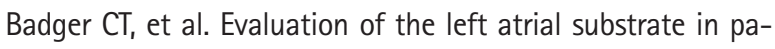
tients with lone atrial fibrillation using delayed-enhanced $\mathrm{MRI}$ : implications for disease progression and response to catheter ablation. Heart Rhythm 2010;7:1475-1481.

29. Akoum N, Daccarett M, McGann C, Segerson N, Vergara G, Kuppahally $S$, et al. Atrial fibrosis helps select the appropriate patient and strategy in catheter ablation of atrial fibrillation: a DE-MRI guided approach. J Cardiovasc Electrophysio/ 2011;22: 16-22.

30. Beinart R, Khurram IM, Liu S, Yarmohammadi H, Halperin HR, Bluemke DA, et al. Cardiac magnetic resonance T1 mapping of left atrial myocardium. Heart Rhythm 2013;10:1325-1331.

31. Fluckiger JU, Goldberger JJ, Lee DC, Ng J, Lee R, Goyal A, et al. Left atrial flow velocity distribution and flow coherence using four-dimensional FLOW MRI: a pilot study investigating the impact of age and Pre- and Postintervention atrial fibrillation on atrial hemodynamics. J Magn Reson Imaging 2013;38:580587.

32. Yamamoto $M$, Seo $Y$, Kawamatsu N, Sato $K$, Sugano A, Machino-Ohtsuka $T$, et al. Complex left atrial appendage morphology and left atrial appendage thrombus formation in patients with atrial fibrillation. Circ Cardiovasc Imaging 2014;7:337-343.

33. Fatkin D, Kelly RP, Feneley MP. Relations between left atrial appendage blood flow velocity, spontaneous echocardiographic contrast and thromboembolic risk in vivo. J Am Coll Cardiol 1994;23:961-969.

34. Beinart R, Heist EK, Newell JB, Holmvang G, Ruskin JN, Mansour $M$. Left atrial appendage dimensions predict the risk of 
stroke/TIA in patients with atrial fibrillation. $J$ Cardiovasc Electrophysiol $2011 ; 22: 10-15$.

35. Mügge A, Kuhn H, Nikutta P, Grote J, Lopez JA, Daniel WG. Assessment of left atrial appendage function by biplane transesophageal echocardiography in patients with nonrheumatic atrial fibrillation: identification of a subgroup of patients at increased embolic risk. J Am Coll Cardiol 1994;23:599-607.

36. Kishima H, Mine T, Ashida K, Sugahara M, Kodani T, Masuyama T. Does Left Atrial Appendage Morphology Influence Left Atrial Appendage Flow Velocity? Circ J 2015;79:1706-1711.

37. Fukushima K, Fukushima N, Kato K, Ejima K, Sato H, Fukushima $K$, et al. Correlation between left atrial appendage morphology and flow velocity in patients with paroxysmal atrial fibrillation. Eur Heart J Cardiovasc Imaging 2016;17:59-66.

38. Di Biase L, Santangeli P, Anselmino M, Mohanty P, Salvetti I, Gili $S$, et al. Does the left atrial appendage morphology correlate with the risk of stroke in patients with atrial fibrillation? Results from a multicenter study. J Am Coll Cardiol 2012;60: 531-538.

39. Nedios S, Kornej J, Koutalas E, Bertagnolli L, Kosiuk J, Rolf S, et al. Left atrial appendage morphology and thromboembolic risk after catheter ablation for atrial fibrillation. Heart Rhythm 2014; $11: 2239-2246$.

40. Shin SY, Na JO, Lim HE, Choi CU, Choi Jl, Kim SH, et al. Improved endothelial function in patients with atrial fibrillation through maintenance of sinus rhythm by successful catheter ablation. J Cardiovasc Electrophysiol 2011;22:376-382.

41. Tousoulis D, Zisimos K, Antoniades C, Stefanadi E, Siasos G,

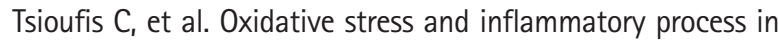
patients with atrial fibrillation: the role of left atrium distension. Int J Cardiol 2009;136:258-262.

42. Makin AJ, Blann AD, Chung NA, Silverman SH, Lip GY. Assessment of endothelial damage in atherosclerotic vascular disease by quantification of circulating endothelial cells. Relationship with von Willebrand factor and tissue factor. Eur Heart J 2004;25:371-376.

43. Chung MK, Martin DO, Sprecher D, Wazni O, Kanderian A, Carnes $C A$, et al. C-reactive protein elevation in patients with atrial arrhythmias: inflammatory mechanisms and persistence of atrial fibrillation. Circulation 2001;104:2886-2891.

44. Hermida J, Lopez FL, Montes R, Matsushita K, Astor BC, Alonso A. Usefulness of high-sensitivity $C$-reactive protein to predict mortality in patients with atrial fibrillation (from the Atherosclerosis Risk In Communities [ARIC] Study). Am J Cardiol 2012;109:95-99.

45. Lip GY, Lowe GD, Rumley A, Dunn FG. Increased markers of thrombogenesis in chronic atrial fibrillation: effects of warfarin treatment. Br Heart J 1995;73:527-533.
46. Heppell RM, Berkin KE, McLenachan JM, Davies JA. Haemostatic and haemodynamic abnormalities associated with left atrial thrombosis in non-rheumatic atrial fibrillation. Heart 1997;77:407-411.

47. Lip GY, Lane D, Van Walraven C, Hart RG. Additive role of plasma von Willebrand factor levels to clinical factors for risk stratification of patients with atrial fibrillation. Stroke 2006; 37:2294-2300.

48. Cooke JP. Asymmetrical dimethylarginine: the Uber marker? Circulation 2004;109:1813-1818.

49. Matsuoka $H_{1}$ Itoh $S$, Kimoto $M$, Kohno $K$, Tamai $O$, Wada $Y$, et al. Asymmetrical dimethylarginine, an endogenous nitric oxide synthase inhibitor, in experimental hypertension. Hypertension 1997;29:242-247.

50. Abbasi F, Asagmi T, Cooke JP, Lamendola C, McLaughlin T, Reaven $\mathrm{GM}$, et al. Plasma concentrations of asymmetric dimethylarginine are increased in patients with type 2 diabetes mellitus. Am J Cardiol 2001;88:1201-1203.

51. Miyazaki H, Matsuoka H, Cooke JP, Usui M, Ueda S, Okuda S, et al. Endogenous nitric oxide synthase inhibitor: a novel marker of atherosclerosis. Circulation 1999;99:1141-1146.

52. Skanes AC, Healey JS, Cairns JA, Dorian P, Gillis AM, McMurtry MS, et al. Focused 2012 update of the Canadian Cardiovascular Society atrial fibrillation guidelines: recommendations for stroke prevention and rate/rhythm control. Can J Cardio/ 2012; 28:125-136.

53. Cowan $C$, Healicon R, Robson I, Long WR, Barrett J, Fay M, et al. The use of anticoagulants in the management of atrial fibrillation among general practices in England. Heart 2013; 99:1166-1172.

54. O'Brien EC, Holmes DN, Ansell JE, Allen LA, Hylek E, Kowey PR, et al. Physician practices regarding contraindications to oral anticoagulation in atrial fibrillation: findings from the Outcomes Registry for Better Informed Treatment of Atrial Fibrillation (ORBIT-AF) registry. Am Heart J 2014;167:601-609.

55. Sacco RL, Kasner SE, Broderick JP, Caplan LR, Connors JJ, Cule-

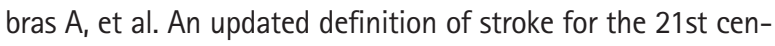
tury: a statement for healthcare professionals from the American Heart Association/American Stroke Association. Stroke 2013;44:2064-2089.

56. Brott T, Tomsick T, Feinberg W, Johnson C, Biller J, Broderick J, et al. Baseline silent cerebral infarction in the Asymptomatic Carotid Atherosclerosis Study. Stroke 1994;25:1122-1129.

57. Hara M, Ooie T, Yufu K, Tsunematsu Y, Kusakabe T, Ooga M, et al. Silent cortical strokes associated with atrial fibrillation. Clin Cardiol 1995;18:573-574.

58. Cha MJ, Park HE, Lee MH, Cho Y, Choi EK, Oh S. Prevalence of and risk factors for silent ischemic stroke in patients with atri- 
al fibrillation as determined by brain magnetic resonance imaging. Am J Cardiol 2014;113:655-661.

59. Marfella R, Sasso FC, Siniscalchi M, Cirillo M, Paolisso P, Sardu $C_{1}$ et al. Brief episodes of silent atrial fibrillation predict clinical vascular brain disease in type 2 diabetic patients. J Am Coll Cardiol 2013;62:525-530.

60. Kalantarian S, Stern TA, Mansour M, Ruskin JN. Cognitive impairment associated with atrial fibrillation: a meta-analysis. Ann Intern Med 2013;158:338-346.

61. Gaita F, Corsinovi L, Anselmino M, Raimondo C, Pianelli $M_{1}$ Toso $E_{1}$ et al. Prevalence of silent cerebral ischemia in paroxysmal and persistent atrial fibrillation and correlation with cognitive function. J Am Coll Cardiol 2013;62:1990-1997.

62. Roy D, Talajic M, Dorian P, Connolly S, Eisenberg MJ, Green M, et al. Amiodarone to prevent recurrence of atrial fibrillation. Canadian Trial of Atrial Fibrillation Investigators. N Engl J Med 2000;342:913-920.

63. Bonanno C, Paccanaro M, La Vecchia L, Ometto R, Fontanelli A. Efficacy and safety of catheter ablation versus antiarrhythmic drugs for atrial fibrillation: a meta-analysis of randomized trials. J Cardiovasc Med 2010;11:408-418.

64. Jais P, Cauchemez B, Macle L, Daoud E, Khairy P, Subbiah R, et al. Catheter ablation versus antiarrhythmic drugs for atrial fibrillation: the A4 study. Circulation 2008;118:2498-2505.

65. Pappone C, Augello G, Sala S, Gugliotta F, Vicedomini G, Gulletta $S$, et al. A randomized trial of circumferential pulmonary vein ablation versus antiarrhythmic drug therapy in paroxysmal atrial fibrillation: the APAF Study. J Am Coll Cardiol 2006; 48:2340-2347.

66. Piccini JP, Lopes RD, Kong MH, Hasselblad V, Jackson K, AlKhatib SM. Pulmonary vein isolation for the maintenance of sinus rhythm in patients with atrial fibrillation: a meta-analysis of randomized, controlled trials. Circ Arrhythm Electrophysiol 2009;2:626-633.

67. Bunch TJ, Crandall BG, Weiss JP, May HT, Bair TL, Osborn JS, et al. Patients treated with catheter ablation for atrial fibrillation have long-term rates of death, stroke, and dementia similar to patients without atrial fibrillation. J Cardiovasc Electrophysiol $2011 ; 22: 839-845$.

68. Reynolds MR, Gunnarsson CL, Hunter TD, Ladapo JA, March JL, Zhang $M$, et al. Health outcomes with catheter ablation or antiarrhythmic drug therapy in atrial fibrillation: results of a propensity-matched analysis. Circ Cardiovasc Qual Outcomes 2012;5:171-181.

69. Chang CH, Lin JW, Chiu FC, Caffrey JL, Wu LC, Lai MS. Effect of radiofrequency catheter ablation for atrial fibrillation on morbidity and mortality: a nationwide cohort study and propensity score analysis. Circ Arrhythm Electrophysio/ 2014;7:76-
82.

70. Haissaguerre M, Jais P, Shah DC, Takahashi A, Hocini M, Quiniou $\mathrm{G}$, et al. Spontaneous initiation of atrial fibrillation by ectopic beats originating in the pulmonary veins. N Engl J Med 1998;339:659-666.

71. Oral H, Chugh A, Ozaydin M, Good E, Fortino J, Sankaran S, et al. Risk of thromboembolic events after percutaneous left atrial radiofrequency ablation of atrial fibrillation. Circulation 2006; 114:759-765.

72. Nademanee K, Schwab MC, Kosar EM, Karwecki M, Moran $M D$, Visessook N, et al. Clinical outcomes of catheter substrate ablation for high-risk patients with atrial fibrillation. J Am Coll Cardiol 2008;51:843-849.

73. Bunch TJ, Crandall BG, Weiss JP, May HT, Bair TL, Osborn JS, et al. Warfarin is not needed in low-risk patients following atrial fibrillation ablation procedures. J Cardiovasc Electrophysio/ 2009; 20:988-993.

74. Themistoclakis $S$, Corrado A, Marchlinski FE, Jais $P$, Zado $E$, Rossillo $A$, et al. The risk of thromboembolism and need for oral anticoagulation after successful atrial fibrillation ablation. J Am Coll Cardiol 2010;55:735-743.

75. Saad EB, d'Avila A, Costa IP, Aryana A, Slater C, Costa RE, et al. Very low risk of thromboembolic events in patients undergoing successful catheter ablation of atrial fibrillation with a CHADS2 score $\leq 3$ : a long-term outcome study. Circ Arrhythm Electrophysiol 2011;4:615-621.

76. Yagishita A, Takahashi Y, Takahashi A, Fujii A, Kusa S, Fujino T, et al. Incidence of late thromboembolic events after catheter ablation of atrial fibrillation. Circ J 2011;75:2343-2349.

77. Guiot A, Jongnarangsin $K$, Chugh A, Suwanagool A, Latchamsetty $R$, Myles JD, et al. Anticoagulant therapy and risk of cerebrovascular events after catheter ablation of atrial fibrillation in the elderly. J Cardiovasc Electrophysiol 2012;23:36-43.

78. Friberg L, Tabrizi F, Englund A. Catheter ablation for atrial fibrillation is associated with lower incidence of stroke and death: data from Swedish health registries. Eur Heart J 2016; DOI: http://dx.doi.org/10.1093/eurheartj/ehw087

79. Bertaglia E, Zoppo F, Bonso A, Proclemer A, Verlato R, Coro L, et al. Long term follow up of radiofrequency catheter ablation of atrial flutter: clinical course and predictors of atrial fibrillation occurrence. Heart 2004;90:59-63.

80. Medi C, Sparks PB, Morton JB, Kistler PM, Halloran K, Rosso R, et al. Pulmonary vein antral isolation for paroxysmal atrial fibrillation: results from long-term follow-up. J Cardiovasc Electrophysiol 2011;22:137-141.

81. Ouyang F, Tilz R, Chun J, Schmidt B, Wissner E, Zerm T, et al. Long-term results of catheter ablation in paroxysmal atrial fibrillation: lessons from a 5-year follow-up. Circulation 2010; 
122:2368-2377.

82. Wokhlu A, Hodge DO, Monahan KH, Asirvatham SJ, Friedman PA, Munger TM, et al. Long-term outcome of atrial fibrillation ablation: impact and predictors of very late recurrence. J Cardiovasc Electrophysiol 2010;21:1071-1078. 